of $5^{\frac{1}{2}}$ years, in a plane inclined $I^{\circ} 34^{\prime}$ to the ecliptic; the next return of which it was impossible to observe from the earth's position; which about 1779, August 23, approached Jupiter within o.or of the earth's mean distance from the sun; and which has not been again observed.

At that distance Jupiter's attraction exceeds that of the sun in the proportion of at least 200 to $I$, and the distance from one of the satellites may have been very small. In this way it is not altogether impossible that the comet may have been diverted into an elliptic orbit round Jupiter, and a retrograde motion round the planet would be as likely as a direct motion to ensue. The intervention of a satellite is essential, and this, combined with the observed large angular distance from Jupiter in one part of its orbit, implies a large eccentricity. Should further observations reveal a moderate eccentricity, the impossibility of identity between this satellite and Lexell's comet will be proved.

The Athenæum, May 6. George Forbes.

\section{The Corrosion of Iron and Steel.}

In a letter to Nature of April 16, Dr. Frank Clowes states his belief that pure lead will dissolve to a slight extent in perfectly pure water " as iron did in the experiments made by Whitney and repeated by the American investigators, when they brought iron into contact with water under conditions similar to those which I had secured."

The American investigators here referred to are $\mathrm{W}$. $\mathrm{H}$. Walker, Cederholm, and Bent, who have recently studied the process of the rusting of iron (Journ. Amer. Chem. Soc., 1907, xxix., p. 125I), and agree with Whitney in regarding the whole subject as an electrochemical one.

With reference to the behaviour of lead in contact with water, I have nothing to say, for although the study of the corrosion of metals has been pursued by me for severa months, my observations have not as yet been extended to lead. I wish to point out, however, that if this metal does dissolve to an appreciable extent in water as Dr. Clowes suggests, then the analogy adopted by this gentleman is open to criticism. I have made a very careful stidy of the process of the rusting of iron, and my results point conclusively to the fact that it is primarily the result of acid attack. These results will, I hope, shortly appear in print; it is unnecessary, therefore, to enter into any detail here. Nevertheless, one or two general remarks may prove of interest.

Walker and his co-workers found that if water in which iron has been boiled is concentrated to a few drops, the presence of iron can be detected by chemical means. It is clear that if the concentration of the iron in solution can be increased by the evaporation of the water, as these authors say, the same result should be obtained by protracted boiling of the water and iron, keeping the volume of the former constant by using a reflux condenser.

My experiments show, however, that such is not the case. The presence of traces of iron discovered by Walker, Cederholm, and Bent is not, therefore, to be ascribed to the action of pure water alone, but to that of traces of dissolved carbon dioxide.

In a very interesting series of investigations, Leduc (Comptes rendus, 1906, cxlii., p. 149) has recently shown that all the dissolved air cannot be expelled from water by the mere process of boiling. He further calculates that at least $x$ c.c. of gas remains in a litre of water even after thorough boiling. Since carbon dioxide is not only much more soluble than oxygen and nitrogen, but also combines with the water to form carbonic acid, it is not unreasonable to suppose that a considerable percentage of this residual gas is carbon dioxide. This will effect the solution of a trace of iron. Although this quantity may be too minute to detect at once by chemical means, its concentration can be greatly increased by evaporating to small bulk, when the characteristic reactions for iron may be obtained. $D n$ the other hand, protracted boiling with reflux condenser cannot increase the concentration of the iron, since the amount of carbon dioxide remains the same. The extreme difficulty of removing all traces of this gas from water is not generally realised by chemists, and the precautions adopted by Walker and his co-workers were not sufficiently refined-hence their results. A single molecule of carbonic acid is sufficient, theoretically, to cause the corrosion of iron (see my remarks, NATURE, September 27, 1906), and I have shown that in practice a very few molecules are operative.

There can be no reasonable doubt, therefore, that the electrolytic theory is wholly inadequate.

In a letter to Nature of October II, 1906, Mr. Richardson asks if the rusting of iron is not caused by bacterial agency. As no reply has been given, it may not be out of place to deal with the question here. The suggestion is not new. Schorler, Beythien, Adler, Raumer, and others have directed attention to a bacterium, Gallionella ferruginea, which obtains its life energy by oxidising ferrous carbonate or organic ferrous salts with the precipitation of rust. But no organism has been found capable of feeding on metallic iron. Indeed, if one such were found, it would have to effect the solution of the iron by some presumably acid secretion, and this brings us back to the acid theory of rusting.

\section{J. Newton Friend.}

Fault Lines in the Atlantic.

IN Prof. J. Milne's discourse at the Royal Institution which appeared in NATURE of April 23 is given an interesting map on p. 593 showing the folds and probable direction of fault lines in the Atlantic. In that map is shown the mid-Atlantic " "rise" extending to about $40^{\circ} \mathrm{S}$. The map, however, would have been more interesting had Prof. Milne included in it the recent bathymetrical researches of the Scotia, which were described in a preliminary paper in the Scottish Geographical Magasine in August, r9o5: Here it is shown that the Scottish expedition sounded out this "rise" for a thousand miles further south than Prof. Milne has marked it, and also that that "rise" has probable connection with another running in a more or less E.N.E. and W.S.W. direction from the south of South America through South Georgia and the Sandwich Group, and also from Graham Land, Antarctica, through the South Orkneys and the Sandwich Group, thence passing eastward through Bouvet Island to Madagascar and the east coast of Africa. The extension of the mid-Atlantic "rise" continues the reflection of the South American continent, and again the transverse "rise" reflects the hypothetical and known portions of the coast-line of Antarctica.

WM. S. BRUCE.

\section{The Pollination of the Olive.}

As Knuth's great work on flower pollination, compiled from all available sources, says nothing whatever about the olive, I recently asked Prof. J. E. Coit, of Arizona, to look out for insects upon the flowers. He carefully examined many olive trees in flower at Tucson, and did not find a single insect at the flowers, with the exception of a thrips (apparently Euthrips occidentalis, Pergande), which occurred in great numbers. He kindly sent me some twigs with the Euthrips upon them, and I was able to observe that these insects were profusely dusted with pollen. No bees were seen at all. Prof. Coit" adds :"Olive pollen is formed and shed in such enormous quântities that I think the wind among the branches is the chief agent in pollination. If you jar a large branch of olive while it is in full bloom, a perfect cloud of green pollen will be seen to float away on the breeze."

Arizona, however, is not the original home of the olive, and the purpose of this note is to suggest that those who have an opportunity to see the plant in bloom in Mediterranean and other countries should make some observations.

University of Colorado, May 2 . T. D. A. Cockerell.

\section{The Coloration of Birds' Eggs.}

I SHOuLD be very grateful if anyone could tell me whether there is anything known with regard to the eggcolour of birds. Is there here, by any chance, a field for investigation which may throw light upon the so-called Mendelian phenomena? Or is there yet any explanation of how the egg becomes coloured, or why? 66 Hallam Street, W.
R. L. Leslie. 